\title{
CONSIDERAÇÕES SOBRE O PATRIMÔNIO DA SERRA DO GRONGONZO EM SÃO BENTO DO UNA (PE) NUMA PERSPECTIVA SISTÊMICA DA PAISAGEM
}

\author{
Renata Maria da Silva ${ }^{(a)}$, Maria Betânia Moreira Amador ${ }^{(b)}$ \\ (a) Graduanda em Geografia pela Universidade de Pernambuco (UPE), Campus Garanhuns. Bolsista PIBIC/CNPq \\ 2016-2017, E-mail: renatasbu2008@hotmail.com \\ (b) Prof ${ }^{a}$. Adjunta do Curso de Licenciatura em Geografia na Universidade de Pernambuco (UPE), Campus \\ Garanhuns. E-mail: betaniaamador@yahoo.com.br
}

Eixo: SOLOS E PAISAGEM

\begin{abstract}
Resumo
A pesquisa apresenta um estudo da paisagem geomorfológica da Serra do Grongonzo no município de São Bento do Una (PE) sob abordagem sistêmica. A metodologia usada é de cunho fenomenológica onde é priorizado a abordagem sistêmica, baseia-se em levantamento bibliográfico e de campo e uso de fotografias. O estudo tem como objetivo analisar a paisagem geomorfológica da Serra do Grongonzo, situando a serra no contexto religioso do município, pontuando os principais problemas atuais que contribuem para impactos de forma negativa na paisagem natural, contextualizada na religiosidade local e ambiental.
\end{abstract}

Palavras-chave: Paisagem Geomorfológica. Serra. Abordagem Sistêmica.

\section{INTRODUÇÃO}

Entre as paisagens geomorfológicas espalhadas pelo Agreste Meridional de Pernambuco, destaca-se a Serra do Grongonzo, uma área significativa para os "são bentenses" e que merece um estudo sob abordagem sistêmica. O mesmo possibilita um entendimento de forma integrada fazendo relações entre o homem e a natureza, sendo de fundamental importância para a análise do objeto estudado principalmente por trata-se de estudos ambientais.

Pesquisas relacionadas a Serra são quase inexistentes na literatura. No entanto, há muito a pesquisar e aprofundar acerca dos diversos aspectos a ela relacionados. A paisagem analisada apresenta desmatamento devido à retirada excessiva da vegetação nativa, para dar lugar, sobretudo à agricultura, a falta de um controle ambiental na preservação dessa área é um dos fatores que acarreta e ameaça a paisagem. Outro aspecto observado se refere ao cruzeiro que foi inserido no alto da Serra do Grongonzo pelo pe. Joaquim Alfredo o vigário da cidade no ano de 1900 em comemoração a passagem do século, como manifestação de fé e amor do povo de S. Bento a Jesus Cristo Redentor, neste local, foram realizados vários movimentos religiosos: missas campais, caminhadas e romarias. 
XVII Simpósio Brasileiro

de Geografia Física Aplicada

I Congresso Nacional

de Geografia Física
OS DESAFIOS DA GEOGRAFIA FÍSICA NA FRONTEIRA DO CONHECIMENTO

Instituto de Geociências - Unicamp

Campinas - SP

28 de Junho à 02 de Julho de 2017

Dessa forma, o presente trabalho em andamento tem como objetivo analisar a paisagem geomorfológica da Serra do Grongonzo, sob uma perspectiva sistêmica, situando a serra no contexto religioso do município, pontuando os principais problemas atuais que contribuem para impactos de forma negativa na paisagem natural, contextualizada na religiosidade local e ambiental.

\section{MATERIAL E MÉTODOS}

A metodologia usada está sendo à de cunho fenomenológica, tendo-se Yi Fu Tuan como referência

proeminente. É priorizada a abordagem sistêmica, a qual possibilita analisar a complexidade da área, entendendo-se complexidade sob a concepção de Edgar Morin. Sendo assim, os procedimentos seguem os passos gerais para uma pesquisa, como a leitura bibliográfica com fichamentos adequados às necessidades de análise. Também se realiza trabalhos de gabinete ao catalogar, decodificar e analisar dados colhidos na literatura. Em campo, além das tomadas de fotos para documentar a pesquisa está-se realizando observações no sentido de perceber como estão se apresentando as variáveis nesse projeto tais como religiosidade, meio ambiente em geral, o que inclui desmatamento, violência entre outros. Além de se usar como técnica de pesquisa, a história de vida de alguns moradores antigos da cidade de São Bento, principalmente em relação aos que possuem registro em memória, mas também fotos e escritos diversos que condizem a uma melhor compreensão da religiosidade da referida serra.

\section{RESULTADOS E DISCUSSÃO}

O município de São Bento do Una está localizado na Mesorregião Agreste e na Microrregião Vale do Ipojuca, situada em uma região com topografia pouco acidentada e com uma ocupação predominantemente horizontal inserida na unidade geoambiental do Planalto da Borborema, formada por maciços e outeiros altos de relevo suave ondulado. A geomorfologia do município é influenciada pela ocorrência de fenômenos consequentes a atividades tectônicas de grande alcance, verificando-se a existência de falhas, dobramentos diversos e diques que se inserem neste contexto cristalino. Os tipos de solos predominantes é o Planossolo, Argissol e Neossolos que ocorrem nas elevações.

A Serra do Grongonzo (Figura 01) está localizada no município São Bento do Una a alguns quilômetros da cidade, sua altitude é de aproximadamente 600 metros, apresenta o formato arredondado. 


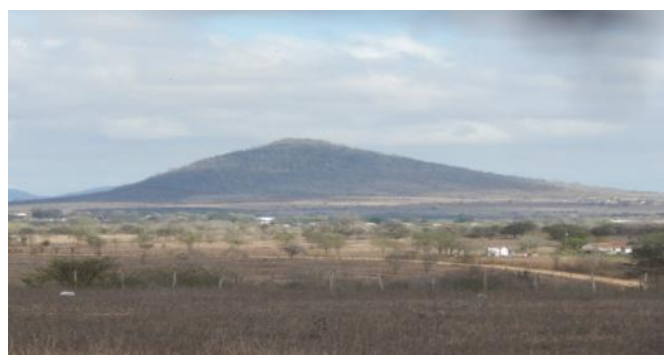

Figura 1 - Serrado Grongonzo

Renata, 2016

A religiosidade do lugar surgiu a partir do primeiro cruzeiro inserido no alto da serra pelo padre desta localidade no ano de 1900. Lá foram realizados diversos movimentos religiosos: romarias, missas campais, caminhadas e teve um turismo incipiente onde as pessoas subiam na serra apenas para ver o cruzeiro e ter uma vista panorâmica da cidade. Atualmente não há nenhum tipo de atividade religiosa no cruzeiro que lá existe, o mesmo encontra-se desgastado. A fraca ou, praticamente nenhuma visita á este lugar está relacionada a diversos fatores, tais como a visível falta de interesse por parte da igreja e da sociedade em geral, associada à insegurança que reina na localidade.

Sobre a origem do nome Grongonzo existe desde os mais antigos escravos informações mística, um dos nomes pesquisados em banto é Grão-Gonzo, grão semente amassada e Grongonzo significa montanha do feitiço. Segundo os descendentes de história, os escravos usavam pontos altos como referência para se localizar, aqueles que vinham do interior de Garanhuns, Pedra e de outras regiões seguiam os rios até São Bento do Una e uma maneira de encontrar o rio Una rio que corta a cidade e direcionava até o Quilombo, era no alto da Serra (pesquisa de campo, 2017).

Próximo a Garanhuns, há o município da Pedra que, por sinal, apresenta uma grande pedra cónica de granito que no passado servia de referência e, os que por ali passavam já avistavam o Grongonzo. Através desse ponto eles faziam a orientação que era empírica pois não havia bússola, na qual a orientação era feita por pontos altos. E assim foi dado o nome à serra. Essa versão é bem disseminada e aceita pelos saobentenses, apesar de não existir uma comprovação histórica. Assim sendo, a paisagem merece ser estudada sob uma ótica sistêmica.

A vegetação da Serra do Grongonzo abriga inúmeras espécies da flora e da fauna típica do bioma Caatinga, como a barriguda, umbuzeiro, pereiro, jurema preta, Ipê, braúna, entre outras espécies. 
Parte desta vegetação foi desmatada e outras estão extintas do local, por questões variáveis e, sobretudo para dar lugar à agricultura. A falta de um controle ambiental, a insensibilidade e/ou ignorância das pessoas em relação ao lugar, a área é então vista mesmo sem nenhum ou pouco valor, o que ameaça ainda mais o lugar. Amador (2016 p. 23) destaca que "notadamente sítios e municípios estão tendo sua biodiversidade gradativamente perdida juntamente com toda a informação biológica, ecológica, geológica, geomorfológica, entre outras, numa rota tendencialmente sem volta."

Dessa forma é importante, sob a abordagem sistêmica, o conhecimento local da biodiversidade do lugar ressaltando-se, ainda, a necessidade de se tomar Yi Fu Tuan como referência pela defesa do lugar através de sua obra intitulada Topofilia entendida como afeição "pelo lugar”. Portanto, a paisagem ainda pode ser concebida como um instrumento de valorização da experiência religiosa e ambiental.

\section{CONCLUSÕES}

Estudos relacionados a Serra do Grongonzo são quase inexistentes na literatura. Entretanto, há muito a pesquisar e aprofundar acerca dos diversos aspectos relacionados a Serra do Grongonzo, sobretudo na questão religiosa e ambiental. Considera-se ainda que, preliminarmente, a paisagem geomorfológica, não é devidamente percebida pelos habitantes da cidade. Nota-se a necessidade da criação de políticas públicas que sejam voltadas para a proteção ambiental do lugar, na intenção de que a população tome conhecimento a respeito do valor que mesma possui. Nesse sentido, com o presente estudo, espera-se contribuir com uma produção acadêmica, mesmo que de maneira introdutória a nível local.

\section{BIBLIOGRAFIA}

AMADOR, Maria Betânia Moreira; BENINI, Sandra Medina. A Complexidade do "Lugar" e "Não-Lugar" numa abordagem geográfico-ambiental. Tupã SP , ANAP 2016. Disponível em www.amigosdanatureza.org.br. Acesso em 20 fev. 2017.

AMADOR, Maria Betânia Moreira. Sistemismo e sustentabilidade: questão interdisciplinar. São Paulo: Scortecci, 2011.

AMADOR, Maria Betânia Moreira. A visão sistêmica e sua contribuição ao espaço pecuário de Venturosa e Pedra no Agreste de Pernambuco, 2008. 316. Tese (Doutorado em Geografia) - Centro de Filosofia e Ciências Humanas. Universidade Federal de Pernambuco, Recife.

CAVALCANTE, Lucas Costa de Souza. Cartografia de paisagens: fundamentos. São Paulo: Oficina de textos, 2014. 
JATOBÁ, Lucivânio; LINS, Rachel Caldas. Introdução a geomorfologia. 4 ed. Recife: Bagaço, 2003.

MORIN. Edgar. Introdução ao pensamento complexo. Tradução de: Eliane Lisboa. Porto Alegre: Sulina 2005.

TUAN, Yi-Fu. Topofilia: Um estudo da percepção, atitudes e valores do meio ambiente. Tradução:DIFEL / Difusão Editorial S. A. São Paulo: DIFEL, 1980. 